\section{ORIGINAL RESEARCH}

\author{
D.C. Suh \\ J.K. Kim \\ J.W. Choi \\ B.S. Choi \\ H.W. Pyun \\ Y.J. Choi \\ M.-H. Kim \\ H.R. Yang \\ H.I. Ha \\ S.J. Kim \\ D.H. Lee \\ C.G. Choi \\ K.D. Hahm \\ J.S. Kim
}

\title{
Intracranial Stenting of Severe Symptomatic Intracranial Stenosis: Results of 100 Consecutive Patients
}

\begin{abstract}
BACKGROUND AND PURPOSE: There are a few reports regarding the outcome evaluation of balloonexpandable intracranial stent placement (BEICS). The purpose of our study was to evaluate the outcome and factors related to the adverse events (AEs) of BEICS.
\end{abstract}

\begin{abstract}
MATERIALS AND METHODS: We evaluated 100 consecutive patients who underwent BEICS. We assessed the procedural success (residual stenosis $<50 \%$ ), AEs (minor strokes, major strokes, and death), clinical outcome, and restenosis ( $>50 \%)$ at 6 months. We also analyzed 18 factors including symptom patterns related to AE rate. Symptom patterns revealed 1) stable patients $(n=73)$ with improving, stationary, or resolved symptoms; and 2$)$ unstable patients $(n=27)$ with gradual worsening or fluctuating symptoms (National Institutes of Health Stroke Scale [NIHSS] $\geq 4$ ) within 2 days before stent placement.
\end{abstract}

RESULTS: The procedural success rate was 99\%. Overall, there were $10(10 \%)$ AEs within the 6 months: $4(4 \%)$ minor strokes, $3(3 \%)$ major strokes, and $3(3 \%)$ deaths including a death from myocardial infarction. AE rate was $4.1 \%$ in stable and $25.9 \%$ in unstable patients. Restenosis at 6 months revealed 0\% (0/59). Good outcome (modified Rankin Scale $\leq 2)$ at 6 months was 97\% (71/73) in stable and $67 \%(18 / 27)$ in unstable patients. Stepwise logistic regression model revealed that symptom pattern (unstable versus stable) was the only significant risk factor $(\mathrm{OR}, 8.167 ; 95 \% \mathrm{Cl}$, 1.933-34.500; $P=.004)$.

CONCLUSION: BEICS revealed a low AE and good outcome rate at 6 months, especially in the stable patients. Midterm outcome was also favorable in the unstable patient group.

I ntracranial atherosclerosis is a major cause of ischemic stroke and accounts for $8 \%$ to $15 \%$ of strokes caused by cerebral atherosclerosis, depending on the population studied. ${ }^{1,2}$ The rate of stroke ipsilateral to the intracranial stenosis (50\%-99\%) is $11 \%$ at 1 year and $14 \%$ at 2 years, despite the use of either warfarin or aspirin and possible vascular risk factor modifications. ${ }^{3}$ Furthermore, the risk for subsequent stroke in the territory of the stenotic artery is $23 \%$ at 1 year and $25 \%$ at 2 years in patients with severe stenosis of $70 \%$ or more. ${ }^{3-5}$

Although successful intracranial artery angioplasty has been attempted, ${ }^{6-9}$ the efficacy of angioplasty alone seems limited because of early elastic arterial recoil and the chronic, geometric arterial changes caused by the negative remodeling leading to restenosis. ${ }^{10,11}$ The recent advent of new-generation stents with a low profile and high flexibility has allowed stentassisted angioplasty to be considered as an alternative approach for the treatment of intracranial stenosis. ${ }^{12-18}$ However, intracranial stent placement, especially with the use of balloon-expandable stents, has not yet been accepted as a routine procedure for the treatment of intracranial atherosclerosis, undoubtedly because of an insufficient outcome evaluation not only from the randomized controlled studies but also from large case series. ${ }^{19}$

\section{Received August 23, 2007; accepted after revision October 29}

From the Departments of Radiology and Research Institute of Radiology (D.C.S., J.W.C., B.S.C., Y.J.C., M.-H.K., H.R.Y., H.I.H., S.J.K., D.H.L., C.G.C.), Neurology (J.S.K.), Anesthesiology and Pain Medicine (K.D.H.), Asan Medical Center, University of Ulsan, College of Medicine, Seoul, Korea; Department of Radiology (J.K.K.), Seoul Veterans Hospital, Seoul, Korea; and the Department of Radiology (H.W.P.), Inha University Hospital, Incheon, Korea.

Please address correspondence to Dae Chul Suh, MD, PhD, Department of Radiology, Asan Medical Center, University of Ulsan, College of Medicine, 388-one Pungnap-2 Dong, Songpa-Gu, Seoul, 138-736, Korea; e-mail: dcsuh@amc.seoul.kr

DOI 10.3174/ajnr.A0922
We evaluated the procedural success rate of intracranial stent placement as well as the clinical outcome, including the adverse events (AEs) and restenosis after balloon-expandable intracranial stent placement (BEICS) in 100 consecutive patients. We also analyzed the factors related to postprocedural AEs occurring during the 30-day and 6-month postprocedural periods.

\section{Materials and Methods}

Among 125 consecutive patients who underwent intracranial stent placement from the prospectively collected neurointerventional data registry from February 2002 to April 2007, 100 consecutive patients were enrolled for this study. Inclusion criterion for intracranial stent placement was symptomatic, severe ( $\geq 70 \%$ ) intracranial stenosis.

We excluded patients from our study who underwent revascularization with a drug-eluting stent $(n=11)$; patients with acute onset of symptoms within 6 hours of the study ( 8 hours for symptoms involving the posterior circulation; $n=6$ ); and patients with incidentally detected, significant, ie, more than $70 \%$ intracranial stenosis noted before coronary artery bypass surgery $(n=3)$ or asymptomatic severe stenosis with decreased ipsilateral perfusion after previous stroke ( $n$ $=3$ ); and patients who underwent stent placement followed by the second revascularization session after intra-arterial thrombolysis or angioplasty $(n=2)$.

Our institutional review board approved this retrospective study. We also obtained written informed consent for the therapy from each patient and their families after we fully explained the nature of the procedure to them.

Patient age ranged from 34 to 80 years (mean, 61 years). There were 78 men and 22 women. Demographic features and risk factors were recorded including hypertension (defined as receiving medication for hypertension or blood pressure $>140 / 90 \mathrm{~mm} \mathrm{Hg}$ on repeated 


\begin{tabular}{|c|c|c|}
\hline Potential Risk Factors & $\begin{array}{c}\text { No. of } \\
\text { Patients }\end{array}$ & $\begin{array}{c}P \\
\text { Value* }^{*}\end{array}$ \\
\hline Age (>60 vs $\leq 60$ y) & 56 vs 44 & 1.0 \\
\hline Sex (male vs female) & 78 vs 22 & .687 \\
\hline Symptom pattern (unstable vs stable) & 27 vs 73 & .004 \\
\hline Initial NIHSS ( $\geq 4$ vs $<4$ ) & 23 vs 77 & .313 \\
\hline Presenting symptom (stroke vs TIA) & 57 vs 43 & 1.0 \\
\hline Time from symptom onset ( $>7$ vs $\leq 7$ day) & 70 vs 30 & .482 \\
\hline Lesion location (anterior vs posterior) & 69 vs 31 & .277 \\
\hline Degree of stenosis ( $\geq 70 \%$ vs $<70 \%$ ) & 49 vs 51 & .049 \\
\hline Length of stenosis ( $\geq 7 \mathrm{vs}<7 \mathrm{~mm}$ ) & 59 vs 41 & .520 \\
\hline Residual stenosis ( $\geq 20 \%$ vs $<20 \%$ ) & 59 vs 41 & .086 \\
\hline Presence of diabetes & 33 & 1.0 \\
\hline Presence of hypertension & 71 & .273 \\
\hline Presence of hyperlipidemia & 26 & .281 \\
\hline Presence of smoking history & 36 & .323 \\
\hline Presence of cardiac disease & 15 & 1.0 \\
\hline Presence of previous stroke & 32 & .722 \\
\hline Level of C-reactive protein ( $\geq 0.2 \mathrm{mg} / \mathrm{dL}$ ) & 48 & .154 \\
\hline Level of homocysteine ( $\geq 15 \mu \mathrm{mol} / \mathrm{L})$ & 28 & .426 \\
\hline
\end{tabular}

Note:-TIA indicates transient ischemic attack; NIHSS, National Institutes of Health Stroke Scale.

* Association between adverse event and each independent factor tested by Fisher exact test.

measurements), diabetes mellitus (defined as receiving medication for diabetes mellitus, fasting blood glucose level $\geq 126 \mathrm{mg} / \mathrm{dL}$, or pancreatic polypeptide 2 level $\geq 200 \mathrm{mg} / \mathrm{dL}$ ), cardiac disease, hyperlipidemia (defined as receiving cholesterol-reducing agents or having overnight fasting cholesterol level $>200 \mathrm{mg} / \mathrm{dL}$ and low-density lipoprotein $>100 \mathrm{mg} / \mathrm{dL}$ ), and current cigarette smoking (current smokers or those who quit smoking $<6$ months) (Table 1 ).

Brain MR imaging was obtained in all patients before stent placement. Diffusion-weighted MR images obtained in 85 patients revealed new ischemic lesions in 67: borderzone $(n=21)$, scattered superficial cortical $(n=15)$, brain stem $(n=15)$, deep perforator $(n$ $=5)$, superficial perforator $(n=5)$, and wedge-shaped pial $(n=6)$ lesion patterns of acute ischemic change. ${ }^{20}$ Fifteen patients who did not undergo diffusion-weighted imaging had a chronic stage of infarct. Thirty-three patients had no recent brain parenchymal lesions. In 43 patients who presented with a transient ischemic attack, there were no parenchymal lesions in 31 and parenchymal lesions in 12 .

Stent placement was performed in the petrocavernous internal carotid artery (ICA) in 35 patients, the M1 portion of the middle cerebral artery in 31 patients, the intracranial vertebral artery (VA) in 20 patients, and the basilar artery (BA) in 14 patients. The number of lesions treated by intracranial stent placement in each patient was either $1(n=94)$ or $2(n=6)$. We used balloon-expandable stents: $\mathrm{RX}$ Driver (Medtronic, Minneapolis, Minn) in 68 vessels, Vision (Guidant, Santa Clara, Calif) in 15, Jostent (Abbott Laboratories, Abbott Park, Ill) in 12, Bx SONIC (Cordis, Miami Lakes, Fla) in 7, S670 stent (Medtronic) in 2, Bx VELOCITY (Cordis) in 1, and Express (Boston Scientific, Maple Grove, Minn) in 1.

A complete history was taken of each patient, and a neurologic examination was performed by independent neurologists who were not involved in the interventional procedure. The occurrence of AEs was evaluated at 30 days after stent placement and again at the 6-month follow-up. If a patient was not followed up in an outpatient clinic, an experienced nurse telephoned the patients $(n=24)$ to evaluate the possibility of any clinically relevant event. The modified Rankin Scale (mRS) was transformed from functional outcome including dependency, living situation, mobility, dressing, and toilet functions. ${ }^{21}$ Ninety-six patients, excluding 3 who died, were clinically followed up for 6 months, including 1 patient who had been lost to follow-up by the time of the 6-month period. Follow-up imaging examination for restenosis at 6 months was done in 59 patients by cerebral angiography $(n=28)$, transcranial Doppler sonography $(n$ $=21)$, and CT angiography $(n=10)$. Restenosis $(>50 \%)$ was defined on cerebral angiography with the use of quantitative vascular analysis (Pie Medical Imaging, Maastricht, the Netherlands) based on the Warfarin-Aspirin Symptomatic Intracranial Disease (WASID) criteria and increased flow velocity on follow-up transcranial Doppler up to the prestenting value. ${ }^{22}$ Restenosis in 10 patients followed by CT angiography was determined by binary estimation $(>50 \%)$ after delineation of traced-stented vessel segments by Advanced Vessel Analysis (Siemens, Erlangen, Germany) or visual inspection of luminal patency along the stented vessel in conjunction with CT perfusion ( $n$ $=7$ ) or on Doppler study below or above the stented vessels $(n=3)$.

\section{Outcome Evaluation and Risk Factor Analysis}

Procedural success was defined as having less than $50 \%$ stenosis after the procedure. AEs were defined as minor stroke, major stroke, or death. Minor stroke was defined as a new, nondisabling neurologic deficit or as an increase in the National Institutes of Health Stroke Scale (NIHSS) by 3 , but which completely resolved within 30 days. ${ }^{21}$ Major stroke was defined as a new neurologic deficit with increased NIHSS by 4 that persisted longer than 30 days. Final outcome at 6 months was determined by mRS (good outcome $\leq 2$, poor outcome $\geq 3$ ).

In consideration of a wide range of onset of symptoms and presenting symptom patterns in our patients, we categorized our patients into the following symptom pattern groups. The stable patient group included those patients who had resolved, improving, or stationary symptoms before the stent placement procedure. The unstable patient group included patients who had progressive or fluctuating neurologic symptoms (NIHSS $\geq 4$ ) corresponding to intracranial stenosis within 2 days before the stent placement procedure. We defined medically refractory patients as those who had a repeated symptom despite having received medical treatment for at least 3 days.

We included the following variables that may affect the AE rate as possible risk factors: age ( $>60$ versus $\leq 60 \mathrm{y}$ ), sex (male versus female), symptom patterns (unstable versus stable), initial NIHSS ( $\geq 4$ versus $<4$ ), time interval from onset of symptoms to procedure $(>7$ versus $\leq 7$ days), presenting symptoms (stroke versus transient ischemic attack), location of lesion (anterior versus posterior circulation $=\mathrm{M} 1+$ ICA versus BA + VA), degree of prestent stenosis ( $\geq 70 \%$ versus $<70 \%$ ), length of stenosis ( $\geq 7$ versus $<7 \mathrm{~mm}$ ), residual stenosis after stent placement $(\geq 20 \%$ versus $<20 \%$ ), presence of vascular risk factors (diabetes, hypertension, hyperlipidemia, smoking, cardiac disease) including the occurrence of previous stroke, elevated C-reactive protein $(\geq 0.2$ versus $<0.2 \mathrm{mg} / \mathrm{dL}$ ), and homocysteinemia ( $\geq 15$ versus $<15 \mu \mathrm{mol} / \mathrm{L}$ ).

\section{Angiointerventional Procedures}

The patients were premedicated with $100 \mathrm{mg}$ of aspirin and either 75 $\mathrm{mg}$ of clopidogrel or $250 \mathrm{mg}$ of ticlopidine at least 3 days before the procedure. All patients were given $200 \mathrm{mg}$ of aspirin and a loading dose of $300 \mathrm{mg}$ of clopidogrel before the procedure, if they were not already taking these medications. We then continued them on $100 \mathrm{mg}$ of aspirin (low-dose regimen) once daily as a permanent medication. In addition, $75 \mathrm{mg}$ of clopidogrel was given once daily for at least 6 months after the procedure. We performed the procedures with the 


\begin{tabular}{|c|c|c|c|c|c|c|c|c|}
\hline \multirow[b]{2}{*}{$\begin{array}{l}\text { Symptom } \\
\text { Pattern } \\
\end{array}$} & \multirow[b]{2}{*}{$\begin{array}{l}\text { No. of } \\
\text { Patients }\end{array}$} & \multirow[b]{2}{*}{$\begin{array}{c}\mathrm{mRS} \leq 2 \text { at } 6 \mathrm{~m} \\
(\%)\end{array}$} & \multicolumn{3}{|c|}{ Event } & \multirow[b]{2}{*}{$\begin{array}{c}\text { No. of Patients With } \\
\text { Event }\end{array}$} & \multirow[b]{2}{*}{$\begin{array}{c}\text { Event Rate } \\
(\%)\end{array}$} & \multirow[b]{2}{*}{$\begin{array}{l}\text { Statistica } \\
\text { Difference }\end{array}$} \\
\hline & & & $\begin{array}{l}\text { Minor } \\
\text { Stroke }\end{array}$ & $\begin{array}{l}\text { Major } \\
\text { Stroke }\end{array}$ & Death & & & \\
\hline Stable & 73 & 71 (97) & 2 & 0 & 1 & 3 & 4.1 & \\
\hline Unstable & 27 & $18(67)$ & 2 & 3 & 2 & 7 & 25.9 & $=.004^{*}$ \\
\hline Total & 100 & $89(89)$ & 4 & 3 & 3 & 10 & 10 & \\
\hline
\end{tabular}

Note:-mRS indicates modified Rankin Scale.

* Fisher exact test.

patients under local anesthesia after intravenous infusion of midazolam 1.5 to $2.5 \mathrm{mg}$, or under neuroleptic anesthesia. During the procedure, each patient received 4000 to 8000 IU of intravenous heparin to attain an activated clotting time of more than 250 seconds. Before treatment, diagnostic cerebral angiography was performed via a transfemoral approach. The procedure began with an injection into the common carotid artery followed by selective angiography of both the ICA and VAs.

A $5 \mathrm{~F}$ to $8 \mathrm{~F}$ sheath or guiding catheter was introduced and was positioned in either the ICA or the VA. The sidearm of the guiding catheter was continuously flushed with pressurized heparinized normal saline and was used for angiography, according to the treatment steps. After crossing the lesion with a 0.014-inch microguidewire or microcatheter, we placed the balloon catheter over the microguidewire and directed the catheter across the lesion.

We predilated the stenotic lesion by using a balloon catheter with a diameter of 1.5 to $2.5 \mathrm{~mm}$ and a length of 10 to $15 \mathrm{~mm}$. Each stent was carefully selected based on the most appropriate availability according to the target vessel size (ie, diameter and length) which was measured on 3D CTA or angiography to avoid oversized stent selection. Residual stenosis of the treated intracranial artery was measured on postprocedural angiography.

An experienced radiographer, who was unaware of the study goal, analyzed the angiographic results by using Quantitative Vascular Analysis (Pie Medical Imaging) based on the WASID methods. ${ }^{22}$ The percentage of diameter stenosis, minimal lumen diameter, and reference diameter before and after stent placement were all measured. On completion of the angioplasty and stent placement, the patients received clopidogrel $75 \mathrm{mg}$ orally once a day for at least 6 months and aspirin $100 \mathrm{mg}$ orally once a day for their entire lifespan. Cilostazol 50 to $100 \mathrm{mg}$ twice daily was added for 1 to 6 months in patients who were regarded as having a long lesion or a stent luminal diameter of less than $2.5 \mathrm{~mm}$.

\section{Statistical Methods}

We evaluated the event (ie, minor stroke, major stroke, or death), after the procedure as an outcome variable. We performed univariate analysis by using the $\chi^{2}$ test or Fisher exact test to assess the effect of each independent variable. Independent variables with a $P$ value of less than .05 on univariate analyses were put into a multivariate logistic regression analysis and then were adjusted for age and sex. Stepwise logistic regression analysis incorporating all independent variables was performed to see which independent variables were eliminated and which ones remained as statistically significant prognostic predictors of adverse events. All reported probability values were 2 sided, and $P$ values of less than .05 were considered statistically significant. We performed all statistical analyses by using an SAS version 8.1 (SAS Institute, Cary, NC).

\section{Results}

Table 1 summarizes the data related to the demographic, angiographic, and cerebrovascular risk factors. Our procedural success rate was 99\%. The overall 10 (10\%) AEs within a 6-month clinical follow-up period included 4 (4\%) minor strokes, $3(3 \%)$ major strokes, and $3(3 \%)$ deaths including a death from myocardial infarction. All 9 (9\%) ipsilateral AEs related to the intracranial stenosis within 6 months developed within the 30-day postprocedural period.

The mean and SD was $69.3 \% \pm 14.4$ for the degree of prestent stenosis and $25.2 \% \pm 16.2$ for residual stenosis. There were 73 stable and 27 unstable patients. The number of patients in whom their conditions were medically refractory was $37(51 \%)$ in stable and $20(74 \%)$ in unstable patients.

Being part of the unstable patient group was significantly related to poor patient prognosis on a Fisher exact test $(P=$ .004) (Table 1). The degree of prestent stenosis was also significantly associated with an increased risk of AEs $(P=.049)$.

Stepwise logistic regression analysis incorporating all independent variables revealed that only the unstable patient group had a significantly higher risk for AEs than the stable group (OR, 8.167; 95\% CI, 1.933-34.500; $P=.004$ ). In the multivariate logistic regression model incorporating symptom patterns and degree of prestent stenosis while adjusting for age and sex, only the unstable patient group had a significantly higher risk for AEs than the stable group (OR, 6.237; 95\% CI, 1.328-29.306; $P=.020)$.

The stable patient group experienced 3 AEs, in contrast to 7 AEs in the unstable patient group (Table 2). There were 5 of 6 major AEs (ie, major stroke plus death) that occurred in the unstable patient group. Three major strokes were related to reocclusion caused by subacute thrombosis after M1 stent placement $(n=2)$ after discharge ( 8 and 9 days after the stent placement procedure), and after VA stent placement $(n=1)$ before discharge ( 5 days after the stent placement procedure). Reocclusions related to subacute thrombosis were noted in 2 patients in whom a Jostent (Abbott Laboratories) was placed in the $\mathrm{M} 1$ and in 1 patient in whom a Driver (Medtronic) was placed in the VA.

Three deaths were related to hemorrhage after BA stent placement in 2 patients and a myocardial infarction in 1 . Death related to myocardial infarction occurred in a 78-yearold patient in the unstable group 22 days after successful intracranial stent placement of the petrous segment and angioplasty of the supraclinoid segment of the ICA.

Follow-up study at 6 months for restenosis was completed in 59 patients. Angiographic follow-up in 28 patients revealed stenosis of a mean $34 \% \pm 0.19 \mathrm{SD}$. No definite restenosis was 
seen on CTA and Doppler study, therefore indicating no restenosis in our study patients $(0 / 59)$.

\section{Discussion}

Our study revealed that BEICS can lead to a good outcome ( $\mathrm{mRS} \leq 2)$ in $97 \%$ of stable patients and $67 \%$ in unstable patients. The overall AE rate after intracranial stent placement within the 30-day postprocedural period was 10\% (9\% ipsilateral AE rate). When we assessed the results according to the presenting symptom groups, our study surprisingly revealed a difference in the AE rate between the 2 presenting symptom pattern groups after intracranial stent placement (ie, the symptom patterns in the stable group showed only a $4.1 \% \mathrm{AE}$ rate, whereas the $\mathrm{AE}$ rate of the symptom patterns in the unstable group was $25.9 \%$ ). To the best of our knowledge, this is the first report to demonstrate a very low risk for BEICS in stable patients as well as the existence of a high-risk patient group for intracranial stent placement.

In some aspects, our results correspond to the high-stroke risk in patients enrolled early ( $\leq 17$ days) in the WASID study (15\% versus $8 \%$ during 1 year for ipsilateral stroke $)^{3}$ and the report of Thijs et $\mathrm{al}^{23}$ in that patients whose symptomatic intracranial atherosclerosis failed antithrombotic therapy had a very high rate of cerebral ischemic events (55.8\%), ie, 29 of their 52 study patients. Gupta et al $^{16}$ also reported a high rate of complications up to $50 \%$ in urgent revascularization of acute symptomatic intracranial stenosis by stent placement and thereby suggested that patient selection, procedure timing, and periprocedural medical treatment are critical factors for reducing periprocedural morbidity and mortality.

The stable patients in our study may have had a more favorable natural clinical course than the unstable patients after the events at the time of symptom onset because the 1-yearipsilateral stroke risk in patients with more than $70 \%$ stenosis is $22.5 \%$, whereas the 2 -year cumulative risk is $24.6 \%$ according to the WASID subgroup analysis, ${ }^{3}$ thus indicating only a $2.1 \%$ per year risk for stroke if the patients were stable for 1 year after the qualifying event. However, the period of symptom onset in our study between the qualifying event (onset symptom) and stent placement was a mean of 36 days (range, 1-180 days) in stable patients and a mean of 11 days (range, 1-60 days) in unstable patients. In consideration of the 1-year ipsilateral stroke risk of $22.5 \%$ in the WASID trial, the $4.1 \%$ event rate in our patients is still much lower than that of the WASID trial, at least during the first year.

The Stent placement of Symptomatic Atherosclerotic Lesions in the Vertebral or Intracranial Arteries (SSYLVIA) study showed that the frequency of stroke in the territory of a stented intracranial artery was $7.2 \%$ at 30 days and $10.9 \%$ at 1 year after the stent placement. ${ }^{24}$ Although use of balloon-expandable coronary stents is not permitted in the United States, the recent study with the Wingspan stent system (Boston Scientific), a self-expandable stent, showed ipsilateral stroke or death rates of $4.5 \%$ at 30 days and $7 \%$ at 6 months. ${ }^{25}$ Another Wingspan study revealed that major periprocedural complication rates reached up to $6.1 \%$ at 30 days including a mortality rate of $4.9 \% .^{26}$

In consideration that the Wingspan studies and SSYLVIA included only stable patients for at least 7 days after a stroke $e^{24,25}$ and SSYLVIA also included $29.5 \%$ extracranial ver- tebral arterial lesions, the AE rate in the stable symptom pattern group was low in our study. Our results cannot be directly compared with those of either of these previous studies because of our shorter follow-up period, the retrospective nature of our study, and our data are from a large, single-center experience performed primarily by a highly experienced specialist in this field. However, our study does provide evidence that BEICS can be safely performed with a low AE rate.

Although the increased event rate in the unstable patient group may be related to many undetermined factors, we attribute the high rate of major AEs in the unstable patient group compared with the stable patient group, in some aspects, to subacute thrombosis or hyperperfusion, ${ }^{27}$ which might be regarded as 2 major complications leading to major AEs within the 30-day postprocedural period in our data. ${ }^{28,29}$ Insufficient control of risk factors or antiplatelet medication before intracranial stent placement may also have contributed to the high event rate in our unstable patient group. ${ }^{30,31}$ Several procedural and patient factors have been shown to predict the occurrence of subacute stent thrombosis, including longer length of the stent, smaller minimum luminal stent diameter, persistent dissection, and multivessel intervention. ${ }^{32}$ However, it is noteworthy that characteristics of the lesion, including length and degree of stenosis which were significant in intracranial angioplasty, were not related to the outcome of intracranial stent placement in our study. ${ }^{33}$

We assume that unstable patients seem to have either unstable plaque in a hemodynamically unstable condition or a hypercoagulable status. ${ }^{34}$ Therefore, stabilization of the lesion by medication, including an antiplatelet agent, statin, or angioplasty, followed by a second-session stent placement, may improve the outcome of the unstable group of patients. ${ }^{15} \mathrm{Be}$ cause of the emergent nature of the procedure in unstable patients, a loading dose of aspirin $100 \mathrm{mg}$ orally, clopidogrel $300 \mathrm{mg}$ orally (or $600 \mathrm{mg}$ orally, unless there is significant early ischemic change leading to hemorrhage) at least 3 hours before the procedure, and a statin ( $80 \mathrm{mg}$ of atorvastatin) at a mean of 12 hours before the procedure may improve clinical outcome by improvement of endothelial function, vasodilation, direct antithrombotic effect, and anti-inflammatory actions. ${ }^{35}$ An adjunctive platelet glycoprotein IIb/IIIa receptor inhibitor such as tirofiban or abciximab may be used as a rescue management in cases of procedure-related thrombosis. Additional randomized controlled studies will be required for more effective management of such unstable patients.

There were 2 deaths among the 14 stent placement procedures of the BA in our study that were related to hemorrhage. Although the overall mortality rate was $3 \%$, this is certainly high $(14.2 \%)$ in a single vascular territory. In addition to hyperperfusion or anticoagulation problems, perforation of the vessel wall related to the balloon or to microguidewire manipulation could also be possible causes. Such technical problems or insufficient periprocedural management may suggest the existence of a learning curve of the complicated intracranial stent placement procedure because 4 of 5 major AEs, including 2 deaths, occurred in the first 50 patients in our study. The patient who underwent ipsilateral concomitant stent placement and such a complex procedure might have increased the risk for an adverse procedural outcome. Therefore, we do not believe that this high mortality is solely related to the particu- 
lar vascular territory of the basilar artery group, though a further subgroup study would be necessary to prove this assumption.

Our study revealed that all AEs developed 1 month after intracranial stent placement and that there was no recurrence of stroke within 6 months after stent placement. Although follow-up was not complete and cerebral angiography follow-up was obtained only in 28 patients in our study, it was surprising that there was a $0 \%(0 / 59)$ restenosis rate of balloon-expandable stent placement compared with the $33 \%$ restenosis rate of SSYLVIA. Symptomatic recurrence seemed to be low in our study after intracranial stent placement, in contrast to SSYLVIA in which the frequency of stroke was $10.9 \%$ during the first postprocedure year. ${ }^{24}$ Additional follow-up studies will be required to evaluate the rate of restenosis as well as recurrence of symptoms.

The limitation of our study was that factors related to the AE were not prospectively analyzed. Prospective randomized studies may further elucidate the prognosis of the different presenting symptom patterns because the prognosis of the unstable patients can be much worse than that of stable patients unless the intracranial stenosis was relieved by stent placement.

\section{Conclusion}

Stent placement of intracranial arteries has a high initial procedural success rate (99\%) and acceptable AE rate (10\%) in our study. The AE rate was much lower in the stable patient group $(4.1 \%)$ compared with the unstable patient group (25.9\%), thus demonstrating that BEICS can be safely performed in stable patients and the AE rate of intracranial stent placement should be evaluated differently in unstable patients.

\section{Acknowledgments}

We thank the assistance of Eun Ja Yoon in preparation of this manuscript; Sun Moon Whang, BS, Eun Hye Kim, RN, and Ji Young Mun, RN, for collecting data on the patients; and Bonnie Hami, MA, Department of Radiology, University Hospitals of Cleveland, Cleveland, Ohio, for editorial assistance in preparation of this manuscript.

\section{References}

1. Sacco RL, Kargman DE, Gu Q, et al. Race-ethnicity and determinants of intracranial atherosclerotic cerebral infarction. The Northern Manhattan Stroke Study. Stroke 1995;26:14-20

2. Wityk RJ, Lehman D, Klag M, et al. Race and sex differences in the distribution of cerebral atherosclerosis. Stroke 1996;27:1974-80

3. Kasner SE, Chimowitz MI, Lynn MJ, et al. Predictors of ischemic stroke in the territory of a symptomatic intracranial arterial stenosis. Circulation 2006;113:555-63

4. Chimowitz MI, Lynn MJ, Howlett-Smith H, et al. Comparison of warfarin and aspirin for symptomatic intracranial arterial stenosis. $N$ Engl J Med 2005;352:1305-16

5. Kern R, Steinke W, Daffertshofer M, et al. Stroke recurrences in patients with symptomatic vs asymptomatic middle cerebral artery disease. Neurology 2005;65:859-64

6. Yoon W, Seo JJ, Cho KH, et al. Symptomatic middle cerebral artery stenosis treated with intracranial angioplasty: experience in 32 patients. Radiology 2005;237:620-26

7. Marks MP, Marcellus ML, Do HM, et al. Intracranial angioplasty without stenting for symptomatic atherosclerotic stenosis: long-term follow-up. AJNR Am J Neuroradiol 2005;26:525-30
8. Chaturvedi S, St Pierre ME, Bertasio B. Cerebral angioplasty practice at major medical centers in the United States. Neuroradiology 2000;42:218-20

9. Marks MP, Wojak JC, Al-Ali F, et al. Angioplasty for symptomatic intracranial stenosis: clinical outcome. Stroke 2006;37:1016-20

10. Dangas G, Fuster V. Management of restenosis after coronary intervention. Am Heart J 1996;132:428-36

11. Klues HG, Radke PW, Hoffmann R, et al. [Pathophysiology and therapeutic concepts in coronary restenosis]. Herz 1997;22:322-34

12. Gomez CR, Misra VK, Liu MW, et al. Elective stenting of symptomatic basilar artery stenosis. Stroke 2000;31:95-99

13. Levy EI, Horowitz MB, Koebbe CJ, et al. Transluminal stent-assisted angioplasty of the intracranial vertebrobasilar system for medically refractory, posterior circulation ischemia: early results. Neurosurgery 2001;48:1215-21; discussion 1221-23

14. Lylyk P, Cohen JE, Ceratto R, et al. Angioplasty and stent placement in intracranial atherosclerotic stenoses and dissections. AJNR Am J Neuroradiol 2002;23:430-36

15. Levy EI, Hanel RA, Bendok BR, et al. Staged stent-assisted angioplasty for symptomatic intracranial vertebrobasilar artery stenosis. J Neurosurg 2002;97:1294-301

16. Gupta R, Schumacher HC, Mangla S, et al. Urgent endovascular revascularization for symptomatic intracranial atherosclerotic stenosis. Neurology 2003;61:1729-35

17. Levy EI, Hanel RA, Boulos AS, et al. Comparison of periprocedure complications resulting from direct stent placement compared with those due to conventional and staged stent placement in the basilar artery. J Neurosurg 2003;99:653-60

18. de Rochemont Rdu M, Turowski B, Buchkremer M, et al. Recurrent symptomatic high-grade intracranial stenoses: safety and efficacy of undersized stentsinitial experience. Radiology 2004;231:45-49

19. Sacco RL, Adams R, Albers G, et al. Guidelines for prevention of stroke in patients with ischemic stroke or transient ischemic attack: a statement for healthcare professionals from the American Heart Association/American Stroke Association Council on Stroke: co-sponsored by the Council on Cardiovascular Radiology and Intervention: the American Academy of Neurology affirms the value of this guideline. Stroke 2006;37:577-617

20. Lee DK, Kim JS, Kwon SU, et al. Lesion patterns and stroke mechanism in atherosclerotic middle cerebral artery disease: early diffusion-weighted imaging study. Stroke 2005;36:2583-88

21. Goldstein LB, Samsa GP. Reliability of the National Institutes of Health Stroke Scale. Extension to non-neurologists in the context of a clinical trial. Stroke 1997;28:307-10

22. Samuels OB, Joseph GJ, Lynn MJ, et al. A standardized method for measuring intracranial arterial stenosis. AJNR Am J Neuroradiol 2000;21:643-46

23. Thijs VN, Albers GW. Symptomatic intracranial atherosclerosis: outcome of patients who fail antithrombotic therapy. Neurology 2000;55:490-97

24. SSYLIVA Study Investigators. Stenting of Symptomatic Atherosclerotic Lesions in the Vertebral or Intracranial Arteries (SSYLVIA): study results. Stroke 2004;35:1388-92

25. Bose A, Hartmann M, Henkes H, et al. A novel, self-expanding, nitinol stent in medically refractory intracranial atherosclerotic stenoses: the Wingspan study. Stroke 2007;38:1531-37

26. Fiorella D, Levy EI, Turk AS, et al. US multicenter experience with the Wingspan stent system for the treatment of intracranial atheromatous disease: periprocedural results. Stroke 2007;38:881-87

27. van Mook WN, Rennenberg RJ, Schurink GW, et al. Cerebral hyperperfusion syndrome. Lancet Neurol 2005;4:877-88

28. Alexandrov AV, Felberg RA, Demchuk AM, et al. Deterioration following spontaneous improvement: sonographic findings in patients with acutely resolving symptoms of cerebral ischemia. Stroke 2000;31:915-19

29. Wagner WH, Cossman DV, Farber A, et al. Hyperperfusion syndrome after carotid endarterectomy. Ann Vasc Surg 2005;19:479-86

30. Jansen O, Schellinger P, Fiebach J, et al. Early recanalisation in acute ischaemic stroke saves tissue at risk defined by MRI. Lancet 1999;353:2036-37

31. Arab D, Lewis B, Cho L, et al. Antiplatelet therapy in anticoagulated patients requiring coronary intervention. J Invasive Cardiol 2005;17:549-54

32. Reynolds MR, Rinaldi MJ, Pinto DS, et al. Current clinical characteristics and economic impact of subacute stent thrombosis. J Invasive Cardiol 2002; 14:364-68

33. Mori T, Fukuoka M, Kazita K, et al. Follow-up study after intracranial percutaneous transluminal cerebral balloon angioplasty. AJNR Am J Neuroradiol 1998;19:1525-33

34. Naghavi M, Libby P, Falk E, et al. From vulnerable plaque to vulnerable patient: a call for new definitions and risk assessment strategies: Part II. Circulation 2003;108:1772-78

35. Patti G, Pasceri V, Colonna G, et al. Atorvastatin pretreatment improves outcomes in patients with acute coronary syndromes undergoing early percutaneous coronary intervention: results of the ARMYDA-ACS randomized trial. J Am Coll Cardiol 2007;49:1272-78 